\title{
Meeting the needs of students with disabilities experiencing homelessness: Federal, community, and educator roles
}

Melissa E. Sullivan-Walker

mshaag@uncg.edu

Marcia L. Rock

Patricia A. Popp

College of William and Mary, pxpopp@wm.edu

Follow this and additional works at: https://scholarworks.wm.edu/aspubs

\section{Recommended Citation}

Sullivan-Walker, Melissa E.; Rock, Marcia L.; and Popp, Patricia A., Meeting the needs of students with disabilities experiencing homelessness: Federal, community, and educator roles (2017).

10.1080/1045988X.2016.1228596

This Article is brought to you for free and open access by the Arts and Sciences at W\&M ScholarWorks. It has been accepted for inclusion in Arts \& Sciences Articles by an authorized administrator of W\&M ScholarWorks. For more information, please contact scholarworks@wm.edu. 


\section{Meeting the needs of students with disabilities experiencing homelessness: Federal, community, and educator roles}

\section{Melissa E. Sullivan-Walker, Marcia L. Rock \& Patricia A. Popp}

To cite this article: Melissa E. Sullivan-Walker, Marcia L. Rock \& Patricia A. Popp (2017) Meeting the needs of students with disabilities experiencing homelessness: Federal, community, and educator roles, Preventing School Failure: Alternative Education for Children and Youth, 61:2, 155-162, DOI: 10.1080/1045988X.2016.1228596

To link to this article: https://doi.org/10.1080/1045988X.2016.1228596

\section{曲 Published online: 26 Sep 2016.}

\section{Submit your article to this journal $\llbracket$}

Llll Article views: 398

View Crossmark data ¿

Citing articles: 1 View citing articles $₫$ 


\title{
Meeting the needs of students with disabilities experiencing homelessness: Federal, community, and educator roles
}

\author{
Melissa E. Sullivan-Walker ${ }^{a}$, Marcia L. Rock ${ }^{a}$, and Patricia A. Popp ${ }^{b}$

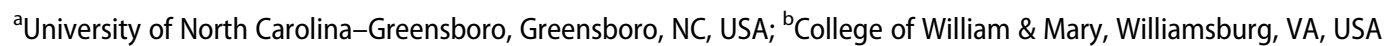

\begin{abstract}
Homelessness is a complex and multifaceted condition that affects 2.5 million, or one in every 30 , children annually. Based on these numbers, it is likely that at least one student has experienced or is experiencing homelessness in most public school classrooms. Sixteen percent of students experiencing homelessness also received services under IDEA in 2014. Authors describe how homelessness impacts the outcomes of students-particularly those with disabilities, what federal policies and protections exist, and how communities lend support. One hallmark of special education, and an essential strategy for serving students experiencing homelessness, is a team approach. Thus, the authors conclude with five practical, team-based tips for school personnel, based on the acronym HOMES, to help ensure they are providing the supports and services these students need.
\end{abstract}

\section{KEYWORDS}

Homeless education; homeless youth; special education; students with disabilities; teaming
Jennifer is 11 years old and lives with her mother, father, and three younger brothers in a motel. Both of her parents work two jobs, so Jennifer is often the caretaker for her younger brothers. At school, Jennifer is quiet and does not socialize with many of her peers. She has been diagnosed with a learning disability in reading and, though her teachers recognize her efforts, she performs below grade level in reading-intensive subjects. Her classroom teacher and resource teacher are often unable to communicate with Jennifer's parents about their daughter's education, and her parents rarely attend meetings at school because they work odd hours and do not have reliable transportation. They wish they could move to a house, or even an apartment, but they live paycheck to paycheck and cannot afford the initial costs.

Seven-year-old Katie and her mother left Katie's father about a month ago, after years of abuse. For now, they are staying in a spare bedroom at her Aunt Jessie's house. Katie's aunt will allow them to stay until they get back on their feet, but Katie's mom has not found a full-time job with decent healthcare benefits and wages that will support their living expenses. Katie is so worried about leaving Aunt Jessie's house that she has lost her appetite and has trouble sleeping. When Katie and her mother moved, Katie began attending a new school, where she is struggling. She misses her old school, where her teacher was kind and motherly, and she knew all of her peers. Katie has not made friends at her new school, and her teachers scold her for falling asleep in class. She is afraid to confide in anybody about her situation.

Chris was 14 when his mother died. The two had been very close and he was devastated. He and his father had argued frequently, but his mother would always mediate. Without her,
Chris and his father fought constantly. After one year, and a particularly terrible fight that almost became violent, Chris finally left his house. He has been on his own for four months, couch surfing between various friends, but he feels he has overstayed his welcome and is running out of options. He has recently taken to staying wherever he can, which often means the bus station, the 24/7 laundromat, or the city park. Chris enjoys school and strives to excel, but struggles without a consistent place to study. Depending on where he stays, his transportation is not always guaranteed, so he is frequently absent. When he is away from school, his meals are often sporadic as well. He confided in his math teacher, but she did not know how to help him. Chris's dream is to graduate and attend college out of state, but he does not even know where to begin; all he knows is that it feels like his life is falling apart.

\section{Youth homelessness: The facts}

As illustrated in the previous vignettes, homelessness is a complex and multifaceted condition that may be fleeting or enduring, and is not limited by ability, gender, age, race, religion, or socioeconomic status. One of the most vulnerable populations experiencing homelessness is children and youth. Under the McKinney-Vento Homeless Assistance Act (2001) Education of Homeless Children and Youth (EHCY) Program, children experiencing homelessness "lack a fixed, regular, and adequate nighttime residence," (42 U.S.C. $§ 11434 \mathrm{~A}[2]$ ), which is defined as a permanent structure, consistently and predictably available, that meets the needs typically met by stable housing.

The most recent statistics pertaining to youth are sobering, with estimates indicating as many as 2.5 million children and

CONTACT Melissa E. Sullivan-Walker mshaag@uncg.edu E Department of Specialized Eduation Services, University of North Carolina-Greensboro, 1300 Spring Garden St., Greensboro, NC 27412, USA.

Color versions of one or more of the figures in this article can be found online at www.tandfonline.com/vpsf.

(C) 2017 Taylor \& Francis Group, LLC 
youth may experience homelessness annually, representing one in every 30 children (Bassuk, DeCandia, Beach, \& Berman, 2014). Given the average class size in most of America's public schools, it is likely that at least one student in most public school classrooms either has experienced or is currently experiencing homelessness. An often overlooked population of children and youth experiencing homelessness is those with disabilities. In a 2014 report on state performance, the National Center for Homeless Education (NCHE) confirmed that 16\% of students experiencing homelessness received special education services under the Individuals with Disabilities Education Act (IDEA).

Why should today's frontline education professionals be concerned? With upwards of two million children and youth, with and without disabilities, experiencing homelessness in U.S. schools, special and general educators are likely to encounter homeless youth in their classrooms even if unbeknownst to them. Considering these startling facts, in what follows, we, as authors, describe how homelessness impacts the schooling of children and youth, particularly those with disabilities; what federal policies and protections exist; how communities lend support; and what action school professionals, referred to variously hereafter as frontline practitioners, can take to positively impact these students' educational experiences.

\section{The impact of homelessness on schooling}

Students experiencing homelessness with or without a disability are at heightened risk for chronic school failure and poor educational outcomes, due, in part, to the many obstacles that hinder their school success. Housing instability and low income often result in high mobility. Students who are highly mobile typically change schools frequently. Each move creates barriers to attendance, such as inability to enroll or lack of transportation, which often lead to chronic absenteeism (Aratani, 2009; The Institute for Children, Poverty, and Homelessness [ICPH], 2015).

\section{Students without disabilities experiencing homelessness}

When students such as Chris and Katie who are experiencing homelessness do attend school, they often face academic and social challenges resulting from frequent interruptions of their educational experiences (Walther-Thomas, Korinek, McLaughlin, \& Williams, 1996). Understandably, students such as Chris and Katie often fall behind academically or lack basic math or reading skills as a result of frequent absences (Moore \& McArthur, 2011). Moreover, they score significantly lower on standardized tests compared to their housed counterparts (Obradovic et al., 2009). During the 2012-2013 school year, less than half of students experiencing homelessness scored at or above the proficient level on state reading and math assessments $-47 \%$ and $44 \%$, respectively (NCHE, 2014). Long-term outcomes for this population are also grim. For instance, they are less likely to complete high school, more likely to have emotional disorders, and at a greater risk for drug or alcohol dependence (Aratani, 2009).

\section{Students with disabilities experiencing homelessness}

Although research abounds on the status and struggles of general education students and their experiences, by comparison the research on the educational impact of homelessness on students with disabilities such as Jennifer appears scant and dated (ICPH, 2015). In 1999, data obtained by the National Center on Family Homelessness confirmed that the number of students with learning disabilities experiencing homelessness is double that of their housed peers, and as a group, children experiencing homelessness are twice as likely to repeat a grade. More recently, Cutuli et al. (2013) discovered that homeless students receiving special services (e.g., ELL services or special education) demonstrated lower levels of initial achievement in math and reading than their housed peers. But difficulties are not limited to academics. Students experiencing homelessness also exhibit behavioral, emotional, and social problems more frequently than their low-income counterparts (Aratani, 2009). Unfortunately, issues such as incomplete records, missing paperwork, and chronic absenteeism often hinder special education evaluation, identification, and services (ICPH, 2015).

As illustrated in the introductory vignettes and based on the above-mentioned statistics, it is clear that children and youth with and without disabilities experiencing homelessness are an especially vulnerable population for whom school can be particularly problematic. Despite the additional challenges they encounter in educational settings, students experiencing homelessness value school and view it as a safe and stable environment with teachers who care (Moore \& McArthur, 2011). Thus, school as a whole-the physical space, the people within it, and the education provided therein-is vital to the success and well-being of children and youth experiencing homelessness, including those with disabilities.

\section{The federal role: Policies and protections}

First and foremost, in order to effectively reach and teach students with and without disabilities who are experiencing homelessness, frontline practitioners must be aware of relevant federal protections and policies. To date, this includes two federal mandates, the Individuals with Disabilities Education Act (2004) and the McKinney-Vento Homeless Assistance Act (McKinney-Vento, 2001) Education for Homeless Children and Youth (EHCY) Program. Although McKinney-Vento is the overarching name for a variety of homeless assistance programs, it is most commonly used to refer to the education portion of the law. In this paper, the authors use McKinney-Vento to reference EHCY. Taken together, IDEA and McKinneyVento protect the rights of students with disabilities experiencing homelessness by ensuring access to education, and to the supports and services they need to succeed.

\section{IDEA}

The Individuals with Disabilities Education Act (IDEA, 2004) is the federal legislation that protects the rights of students, specifically those with disabilities, and ensures their access to a free, appropriate public education (FAPE) in the least restrictive environment (LRE). Part B of IDEA includes several 
provisions to ensure students and their families receive the necessary services and protections. Yell, Katsiyannis, and Bradley (2011) described six critical provisions: zero reject, protection in evaluation, FAPE, LRE, procedural safeguards, and parent participation. These provisions are applicable to all children, regardless of housing status, but homelessness may add a layer of complexity to each. Although frontline practitioners must address all of them, discussing each provision is beyond the scope of this article. Thus, in the sections that follow, the authors focus on the overlap between IDEA and McKinneyVento.

\section{The McKinney-Vento Homeless Assistance Act}

In addition to IDEA, when serving students with and without disabilities who are experiencing homelessness, frontline practitioners must also be knowledgeable about McKinney-Vento (2001). Originally authorized in 1987 as the Stewart B. McKinney Homeless Assistance Act and, most recently, under the Every Student Succeeds Act (ESSA, 2015), McKinney-Vento is the primary federal legislation safeguarding the education of homeless children and youth with and without disabilities. At its heart, McKinney-Vento ensures that students experiencing homelessness receive the services and supports necessary for uninterrupted public schooling, thereby minimizing the adverse impacts on academic performance.

McKinney-Vento (2001) includes provisions for school selection, transportation, immediate enrollment, access to programs and services, and appointment of local homeless education liaisons. In addition, every state must have an office of the state coordinator for the education of homeless children and youth, a position usually designated in the state department of education (McKinney-Vento, 2001). Children and youth experiencing homelessness have the right to remain in their school of origin-the school they were attending when they were last housed or the last school attended-if the parents choose to do so and it is in the child's best interest, as determined by the parents, youth, and school team. Furthermore, they qualify for transportation to and from their school of origin. Under McKinney-Vento, Katie has the option of staying at her previous school, although she may have moved out of the school or even the district boundaries. Moreover, the two local education agencies (LEAs) must agree on a transportation plan for Katie, if necessary, and determine which LEA is financially responsible or if they will share the responsibility (McKinney-Vento, 2001).

Children who qualify as homeless but do not remain in their school of origin must be immediately enrolled in a new school, even if the required paperwork is not available. Thus, if Jennifer's family moved and she changed schools, her new school must enroll and begin serving her immediately, even without previous academic files, vaccination records, or her IEP. Regardless of school choice, students experiencing homelessness must have access to the same programs and services as their housed peers and may not be segregated based on housing status. To ensure McKinney-Vento provisions are met, school district personnel must include local homeless liaisons, who are responsible for ensuring that students experiencing homelessness have full access to the public education to which they are entitled.

\section{IDEA and McKinney-Vento working together}

As mentioned previously, housing status may complicate special education service provision for students with disabilities who are also experiencing homelessness. Nevertheless, LEA personnel must consider and adhere to both laws when serving this population. The intersection of IDEA and McKinneyVento provides opportunities and challenges that can be met when state and school district personnel make the effort to work together across special education and homeless programs. Among the issues that should be addressed are Child Find, special education eligibility, application of Response to Intervention (RtI) efforts during identification and evaluation, immediate enrollment, and the balance of school-of-origin stability with LRE.

Proactive Child Find activities are required by both IDEA (2004) and McKinney-Vento (2001), meaning school districts must actively seek out and identify students with disabilities and those who are experiencing homelessness. In fact, IDEA (2004) specifically lists students who are homeless as a target population that must be reached when identifying children and youth with disabilities. Typical Child Find efforts may fall short when students experiencing homelessness are involved because youth such as Chris, who is couch-surfing and living unsheltered, may be highly mobile. Special education staff and the local homeless education liaison should work together to create a Child Find process that can reach families being served under McKinney-Vento.

Liaisons are responsible for building relationships with community service agencies, such as shelters or food banks. Liaisons should know where homeless families are most likely to be found, what services they typically access, and what languages are most common. Sharing this knowledge with the Child Find team can extend the reach to these families. Possible actions include having Child Find materials available at shelters or soup kitchens, or including Child Find resources in the homeless education packet when enrolling a student identified as homeless. In addition, liaisons must ensure that special educators know what it means to be homeless and how to refer a student for McKinney-Vento services.

Teamwork is also crucial when students experiencing homelessness are referred for special education evaluations. Some localities use their child study team as a mechanism to review the needs of all students who are identified as homeless. If there is suspicion of a disability, team members can begin the identification process expeditiously. Frequent moves can make it difficult for team members to determine whether a student's difficulties are the result of a disability or the lack of an opportunity to learn. Homeless advocates recommend that this ambiguity not be used to deny an evaluation, but as a consideration at the end of the process, noting that IDEA requires the evaluation process begin as soon as a disability is suspected (Julianelle, 2006). Furthermore, schools can make provisions (e.g., through additional funding) to expedite the evaluation process, preventing any highly mobile students from falling through the proverbial cracks if they move before evaluation is complete (Losinski, Katsiyannis, \& Ryan, 2013).

Often used as an initial step in the evaluation process, Response to Intervention (RtI) is a tiered approach to early 
identification of and intervention for students with academic and behavioral needs (RtI Action Network, 2016). School personnel provide evidence-based interventions to struggling students and monitor their progress over time, using the data to make decisions about the intensity and duration of interventions (RtI Action Network, 2016). The lengthy process may adversely affect students experiencing homelessness, and must be a topic of discussion among homeless and special education staff. Although RtI can be beneficial, high mobility can be a barrier to implementation when students are not at a school long enough to benefit from the results of tiered interventions. Special and homeless education staff need to determine how to ensure that RtI implementation does not delay an evaluation when students are homeless and moving frequently.

Although Katie is living with her aunt right now, she and her mother may be forced to move at any time. It may be difficult for Katie's mother to find stable housing without a steady income, or if Katie's father poses a threat. Thus, when Katie makes the transition to a new school, she may benefit from moving right into Tier 2 supports-targeted interventions for students who do not respond to high-quality, universal Tier 1 instruction. As Katie navigates her new classroom and learns to cope with the trauma she has experienced, she may need small group remedial instruction from her teacher, or one-on-one sessions with the school counselor. Receiving these supports, without completing the extensive special education referral process, can help Katie succeed in school immediately. If the tiered interventions do not help Katie, school personnel will have the data necessary to expedite a formal evaluation for a potentially highly mobile student.

Such a process was in place in Jennifer's school. When Jennifer was identified as a struggling student, her teacher began the RtI process. However, she soon began to suspect that Jennifer's home environment was not ideal. She contacted the school social worker, who visited Jennifer's family and confirmed her suspicions, then alerted the RtI team to Jennifer's situation. The school social worker was added to the team for additional support. At the social worker's suggestion, the team gathered RtI data on a truncated timetable and expedited the evaluation, avoiding the possibility that Jennifer would move and change schools before being identified.

McKinney-Vento requires immediate enrollment when a student experiencing homelessness arrives at a new school, even if typically required documentation (e.g., school or immunization records) is missing. Without school records, how can enrollment staff determine whether the child has an IEP? When school records are missing, staff may ask questions such as:

- How many teachers were in your child's last class?

- How many students were there?

- Did your child receive any special services?

- Did you have to sign permission for additional help?

Lack of a current IEP cannot delay enrollment. School districts should develop options for providing support when no IEP is provided but evidence suggests one might exist, and establish systems to prioritize obtaining missing records.

When students experiencing homelessness move, they have the right to remain in their current school, if it is in the student's best interest, even if their new residence is in a different community or even a different school district. When a student also has an IEP, the issue of LRE must also be considered. If Jennifer and her family move in with her grandmother in another town, the IEP team may see the local school there as the option that provides LRE. However, because she is still considered homeless, Jennifer's McKinney-Vento rights also must be taken into account. Remaining in her current school may be in her best interest, if school personnel can provide the necessary services. Rather than seeing the possible tension as one law trumping another, the situation can become an opportunity to examine a broad variety of factors, keeping Jennifer's best interest as the central focus. The district may have a development that allows input from the homeless liaison as part of the IEP process. The liaison may also need to consult with the IEP team when making a best-interest determination about staying in the school of origin. Transportation often has a large fiscal impact, so McKinney-Vento and special education transportation will need to be part of such a conversation, since fiscal responsibility will vary by state and locality.

The examples of intersections between the two laws described above require knowledge of both programs by key stakeholders. At the state level, IDEA requires McKinneyVento representation on state special education advisory committees to ensure that some of the challenges are addressed at a broad policy level. Local school districts may wish to have a parallel process to review and modify, when needed, policies and practices that are not working for students. Cross training and joint training of both school and community staff, to understand who is considered homeless and the basics of special education, can increase the likelihood of essential referrals and collaboration. For example, in Virginia, the special education parent resource centers provide a basic introduction to special education for parents. This training was also provided to shelter staff so they would be able to better support their families when a disability was suspected. Given the complexities of providing transportation under both laws, transportation staff should be included in these conversations. School districts that often share the same highly mobile students can arrange for homeless liaisons, transportation directors, and special education representatives from each LEA to meet, examine data, discuss challenges they have experienced, and decide how they can best work across their districts, increasing communication and stability for their students.

\section{United States Interagency Council on Homelessness}

As evidenced in previous sections, homelessness is a complex and multifaceted problem requiring careful and committed collaboration at all levels. The United States Interagency Council on Homelessness (USICH, or the Council) has been charged by Congress to lead the coordinated federal response to homelessness. The efforts of USICH and its 19 member agencies support state and local efforts to respond to the needs of families and youth experiencing homelessness. Every day, the Council helps to build and strengthen cross-agency partnerships that foster effective teamwork to benefit children such as Jennifer, Chris, and Katie. By encouraging the use of evidence-based practices and backing the efforts of local service providers, the Council is 
working to provide children and youth experiencing homelessness the education to which they are entitled. See Figure 1 for other national-level organizations focused on homeless education.

\section{The community role: The community response to the youth homelessness model}

Federal agencies support a complex network of diverse service providers and funding streams necessary to meet the unique and varying needs of children and youth experiencing homelessness. These needs cannot be met without a unified effort across partners, at all levels (i.e., federal, state, and local; USICH, 2015). Thus, USICH and its member agencies have developed a shared vision for a coordinated community response, bringing together housing, health and behavioral services, community programs, and education. Frontline personnel must go beyond understanding and adhering to the federal policies and protections when serving students with and without disabilities experiencing homelessness, to connecting with community providers who serve youth experiencing homelessness and their families. One way to do so is through actively implementing a coordinated community response to prevent and end youth homelessness (USICH, 2016).

Components of the coordinated community response model include prevention, identification, early intervention, support, and assessment (USICH, 2016). Preventing impoverished or precariously housed families from losing their housing, or youth at risk of leaving their homes from ending up on the streets, is the first step to avoiding homelessness. Identifying and engaging youth experiencing homelessness-with or without disabilities-must be done quickly, whether by child welfare professionals, shelter or outreach workers, communitybased providers, or educators. School personnel are essential to a community's capacity for identification and early intervention, and may need to more actively pursue strategies for outreach and engagement, both within and outside the educational system, on behalf of students experiencing homelessness. Once youth with or without disabilities are identified as homeless,
U.S. Department of Education http://www2.ed.gov/about/inits/ed/supportinghomeless-students/index.html

The Department of Education is a core member of USICH, and a key partner to ending child and youth homelessness throughout the United States. Their website includes important information for educators about the EHCY Program, and links to programs and resources available from pre-k through post-secondary education.

\section{United States Interagency Council on Homelessness (USICH) https://www.usich.gov/}

USICH is an interagency effort focused on federal level collaboration to end homelessness. One particularly valuable section of their website is the searchable tools section, which allows visitors to narrow their search for specific populations, goals, and types of resources.

National Center on Family Homelessness at American Institutes for Research (AIR) http://wwwair.org/center/national-center-familyhomelessness

National Center on Family Homelessness harnesses the expertise of AIR, one of the world's leading research and evaluation organizations, to address the issue of homelessness. Their website includes links to important topics in homelessness, and services for organizations.
National Center for Homeless Education (NCHE) at SERVE

http://www.serve.org/nche

NCHE operates the Department of Education's technical assistance center for the EHCY Program. Here, frontline practitioners can find training and resources on almost any topic relating to educating homeless youth, and up to date contact information for their State Coordinator for Homeless Education, and their district's local homeless liaison.

\section{National Association for the Education of} Homeless Children and Youth (NAEHCY) http://www.naehcy.org

NAEHCY is a national membership association dedicated to the educational success of children and youth experiencing homelessness. Their website includes information on advocacy and policy, educational resources, and their scholarship program for students experiencing homelessness.

\section{National Alliance to End Homelessness http://www.endhomelessness.org/}

The National Alliance to End Homelessness focuses on policy and capacity building. Their website is packed with information about different types of and issues related to homelessness, news, policy, potential solutions, and training opportunities. Their Take Action page informs visitors how to help in the fight against homelessness.

Figure 1. Web-based resources for teams serving students with and without disabilities experiencing homelessness. 
they can receive essential supports tailored to their needs and often "wrapping around," just as supports are individualized and comprehensive in special education. As with identification, an array of needed supports can be provided through schools and school personnel. Finally, assessment of each youth's needs and circumstances, by social workers or by specific program personnel, must be ongoing in order to ensure youth experiencing homelessness, both with and without disabilities, have access and are connected to the most appropriate services.

\section{The educator's role: Teaming to meet the needs of students with disabilities experiencing homelessness}

As school personnel continue to move in the direction of RtI and multitiered systems of supports (MTSS), educational decisions are commonly made by team members, rather than by individual teachers. Thus, many frontline practitioners have a wealth of teaming experience on which to draw when serving students with and without disabilities who are experiencing homelessness. IDEA (2004) guards against unilateral decision making, in part, by requiring a team-based approach to decision making and subsequent service provision for students with disabilities, including those experiencing homelessness.

Special education teams include general educators, special educators, school psychologists, related services personnel, administrators, parents, advocates, and the child, when appropriate (IDEA, 2004). A team that supports youth with disabilities experiencing homelessness should be expanded to include the school counselor, the school social worker, child welfare workers (e.g., shelter staff or other community agency personnel), juvenile justice personnel, and the local homeless liaison. The expanded team members work together not only to meet a student's unique educational needs inherent to his or her disability, but also those that stem from the experience of homelessness.

Despite the aforementioned growing popularity and necessity of team efforts in schools, when it comes to meeting the complex needs of students with disabilities who are experiencing homelessness, guidance for school personnel remains undifferentiated and directed toward individual efforts. The lack of teamwork between school, child welfare, and community personnel can result in efforts being duplicated or services being unintentionally withheld (Palladino, 2009). Although school personnel can take some actions independently, there are laws that govern, models that exist, and evidence that confirms that a team approach is preferred. Thus, the authors encourage frontline practitioners to adopt a team approach for serving students with and without disabilities who are experiencing homelessness. Teaming allows multiple professionals to pool their collective resources and knowledge to provide the most effective services for this unique student population.

\section{Tips for meeting the needs of students with disabilities experiencing homelessness}

As can be seen in the opening vignettes, every family or unaccompanied youth experiencing homelessness has a unique set of circumstances accompanying their situation. Just as no two
IEPs are identical, neither should the services provided to students experiencing homelessness be the same. Thus, we present several universal tips, being mindful of the special education process, USICH's coordinated community response model, and the protections provided by federal policies. The suggested tips can and should be implemented by interdisciplinary teams serving students experiencing homelessness with and without disabilities.

As authors and former frontline practitioners, we acknowledge the demanding lives of teachers, counselors, teaching assistants, administrators, and other essential service providers. Thus, we present the following tips with the often-frenetic environment of a school or classroom in mind. Although this list is by no means exhaustive, we identify some of the most feasible options for school personnel today. The recommendations were developed through an examination of the extant literature, and with evidence-based practices in mind. Using the acronym HOMES, we have emphasized some of the most important concepts and made them easy to remember.

\section{Hold one another accountable}

As previously illustrated through emphasis on the team approach, one single professional cannot address student homelessness; all school personnel must support students with and without disabilities who are experiencing homelessness. Team members serving these students should be prepared to expand both their knowledge and awareness, and to help foster the knowledge and awareness of their colleagues. Preparation and ongoing professional development, covering legal requirements, indicators of homelessness, sensitivity training, and effective instructional strategies should be provided for all school personnel (Walther-Thomas et al., 1996). Essentially, the team is like a coin-educators on one side, social workers and child welfare workers on the other. Each side has its own unique characteristics, but they ultimately work together for one purpose.

Once Chris's teacher was aware of his situation, she realized most teachers in her school were probably just as unfamiliar with the issue. She did some research and discovered that her district had a local homeless liaison dedicated to supporting students experiencing homelessness. She contacted the homeless liaison, who agreed to come to the school and provide professional development for the whole staff. Chris's teacher also asked the homeless liaison for some practitioner-friendly literature and relevant websites, so she could share the information with her colleagues, and they could all become more knowledgeable about youth homelessness, and connect with the resources available in their community.

\section{Open and maintain clear lines of communication}

Though cooperation across professions, such as education and social work, can be difficult, it is essential to the success of students experiencing homelessness. Likewise, communication within a profession, such as between current and former teachers, provides more complete information and allows for more expeditious delivery of services to address student needs. Furthermore, education and community service personnel (e.g., shelter staff, service providers) must also develop effective means of cooperation to support youth and families being 
served by both groups. School personnel can provide shelters with basic information such as academic calendars or school supply lists, or even use McKinney-Vento funds to create a study area in the shelter (Walther-Thomas et al., 1996). Shelter staff or other community service personnel can attend professional development sessions at area schools and provide more information about their agencies and services so educators will be more informed of local supports.

If Katie and her mother must move out of Aunt Jessie's house and into a shelter, lines of communication must be open between all agencies and individuals serving them. If the shelter has an ongoing relationship with the school district, personnel on both sides will know what and how to communicate. Shelter staff can ensure that school personnel know how to best serve Katie based on her housing situation, and her teachers can share important information about educational policies and practices so shelter staff can support her. If it is in Katie's best interest to attend another new school, communication between Katie's current and former teachers will help fill in any gaps in Katie's records and ensure that she is getting the supports she needs.

\section{Maximize student supports}

Both McKinney-Vento (2001) and IDEA (2004) state that students must have access to the services they need to succeed; students with and without disabilities experiencing homelessness often require additional supports, and educators must be prepared to identify and deliver the needed services. By engaging in evidence-based practices, teachers can provide the academic, affective, and basic supports their students need (see Popp, Grant \& Stronge, 2008). If a student experiencing homelessness is referred for special education evaluation, any modifications or accommodations implemented should continue throughout the evaluation process.

Because Chris has lost his mother and left home, he lacks permanent, meaningful connections to adults that care about his well-being. He trusts his math teacher, and even confided in her; she has the opportunity to help him develop positive relationships with other adults and supportive peers through supports such as mentoring programs. She should seek advice and information from the school counselor and community service providers about how to support Chris. One critical skill for Chris to learn is self-advocacy, both in school and beyond, especially if he remains unaccompanied.

To support Jennifer's academic success, her classroom teacher continually collaborates with her special education teacher. Though Jennifer receives most of her reading instruction in the special education classroom, she needs support in her general education classroom during reading-intensive subjects such as science. Her classroom and special education teachers discuss what strategies would be most beneficial for her and how they should be implemented. Both teachers maintain data on Jennifer's progress and share it weekly with each other and the team so they can continually assess Jennifer's goals and development. As Jennifer progresses through school, self-advocacy should be a skill included in her educational plan. She must be taught how and when to advocate for herself, as a student with a disability and a student experiencing homelessness, so she can succeed in school.

\section{Evaluate and monitor student needs}

Ongoing monitoring and evaluation are the keys to ensuring that students with and without disabilities experiencing homelessness receive the most effective instruction and appropriate services (Popp et al., 2008). Sharing formative and summative assessment results with team members and community service providers helps prevent both duplication and exclusion of services. It also ensures that teams can make informed decisions about a student's best interest, especially in cases when the stability of remaining in the school of origin runs counter to the provision of LRE.

Team members can simplify ongoing monitoring and evaluation efforts by using existing evidence-based practices and modifying them as needed. Two potential interventions, primarily used for students with behavioral issues, are Check-In/ Check-Out (CICO; see Wolfe et al., 2016) and Check, Connect, Expect (CCE; see Cheney et al., 2009). In both interventions, a teacher meets with the student before school to check in, review behavioral expectations, and provide a tracking sheet. After school, the same teacher checks out with the student and evaluates social, emotional, and behavioral data, and offers encouragement. CCE goes a step further-after eight weeks, if students have made the required behavioral growth, they begin self-monitoring their behavior, with coach support. This is especially beneficial for students such as Chris and Jennifer who are learning to self-advocate. Rather than track only social, emotional, and behavioral data, team members serving students experiencing homelessness can add academic, affective, and other basic needs. Coaches should be part of the team and provide the CICO or CCE data to the rest of the members so they can analyze student needs and decide who can best meet them. Jennifer, Katie, and Chris all have unique needs that must be met and continually evaluated, and would all benefit from one of these modified approaches.

\section{Support students and their families}

Students are not the only ones facing the difficulties of homelessness; parents or other family members have their own set of obstacles to contend with as well. Parents or guardians of students experiencing homelessness may seem disconnected or uninterested in their child's education; however, that is usually not the reality (Walther-Thomas et al., 1996). Often, the child's parents are so busy trying to secure basic needs that they simply do not have enough time in the day to focus on academics. Rather than assuming parents are inadequate or disengaged, service providers and educators should remain flexible and assume the parents care. Teachers can provide unique ways for parents to be involved and kept abreast of their child's progress.

Because Jennifer's parents work multiple jobs, her teachers should provide several options for her parents to communicate about and be involved in Jennifer's education. They can send a notebook home with important updates on Jennifer's progress or information about school. Her parents can then write back with information or questions. Jennifer's teachers should offer meeting times and locations that are convenient for Jennifer's parents. That may mean meeting outside of school hours, in a public place such as the library, which is easily accessible via public transportation, and would also provide activities for 
Jennifer and her brothers during the meeting. Even though it requires additional effort, including Jennifer's parents in her education as much as possible will benefit everyone.

\section{Concluding thoughts}

Effectively reaching and teaching children and youth experiencing homelessness requires coordinated and sustained efforts by policymakers, community members, and school personnel. With the exception of parents or guardians, school personnel are the adults with whom this vulnerable population of children typically spends the most time. Armed with accurate knowledge, special and general educators and other frontline practitioners can provide direct and indirect school supports as well as serve as advocates for these students, spearheading school, district, or community initiatives that address homelessness and help to alleviate its burdens. That said, the information and tips provided herein are by no means exhaustive. Instead, we, as authors, have offered a starting point for special educators to facilitate a team approach wherein members become more effective in supporting the often invisible children with and without disabilities who are experiencing homelessness and in desperate need of support to maximize their educational success.

\section{Acknowledgments}

The authors would like to acknowledge USICH Deputy Director Jasmine Hayes and the members of the Youth Working Group for their support of this article.

\section{Funding}

This article was supported, in part, by Grant \#H325D110071 from the U.S. Department of Education, Office of Special Education Programs Research to Practice Division. The opinions expressed herein do not necessarily reflect the position or the policy of that agency.

\section{Notes on contributors}

Melissa E. Sullivan-Walker is a fifth year LINK-2-LEAD doctoral scholar in the Department of Specialized Education Services in the School of Education at the University of North Carolina at Greensboro. Her research interests include teacher preparation and development for students experiencing homelessness, and interprofessional education.

Marcia L. Rock is an Associate Professor in the Department of Specialized Education Services in the School of Education at the University of North Carolina at Greensboro. Her research interests are in technology enabled teacher development, eCoaching, effective instruction for students with high incidence disabilities, and classroom/ behavior management.

Patricia A. Popp is the Virginia State Coordinator for the Education of Homeless Children and Youth, Project HOPE-Virginia, which is a collaborative initiative between the Virginia Department of Education and the School of Education at the College of William \& Mary. Patricia also serves as a Clinical Associate Professor in the Curriculum and Instruction Department at the School of Education.

\section{References}

Aratani, Y. (2009, September). Homeless children and youth: Causes and consequences. Retrieved from http://www.nccp.org/publications/pdf/ text_888.pdf.
Bassuk E., DeCandia, C., Beach, C., \& Berman, F. (2014). America's youngest outcasts: A report card on child homelessness. Retrieved from http://www.air.org/sites/default/files/downloads/report/AmericasYoungest-Outcasts-Child-Homelessness-Nov2014.pdf.

Cheney, D. A., Stage, S. A., Hawken, L. S., Lynass, L., Meilenz, C., \& Waugh, M. (2009). A 2-year outcome study of the Check, Connect, and Expect intervention for students at risk for severe behavior problems. Journal of Emotional and Behavioral Disorders, 17(4), 226-243.

Cutuli, J. J., Long, J. D., Chan, C., Desjardins, C. D., Herbers, J. K., Heistad, D., $\ldots$ Masten, A. S. (2013). Academic achievement trajectories of homeless and highly mobile students: Resilience in the context of chronic and acute risk. Child Development, 84(3), 841-857.

Every Student Succeeds Act, 20 U.S.C. $§ 2002$ (2015).

Individuals with Disabilities Education Improvement Act of 2004, 20 U.S. C. $\S 1400$ (2004).

Institute for Children, Poverty \& Homelessness. (2015). American almanac of family homelessness. Retrieved from http://www.icphusa.org/PDF/ americanalmanac/Almanac2015_000_Full.pdf.

Julianelle, P. (2006 May 10). NAEHCY Counsel memorandum: Evaluations for highly mobile students. Memorandum. Retrieved from http://www. naehcy.org/educational-resources/spec-ed.

Losinski, M., Katsiyannis, A., \& Ryan, J. B. (2013). The McKinney-Vento education for homeless children and youth program: implications for special educators. Intervention in School and Clinic, 49(2), 92-98.

McKinney-Vento Homeless Education Assistance Improvements Act of 2001, 42 U.S.C. $\S 11301$. (2001).

Moore, T., \& McArthur, M. (2011). "Good for kids": Children who have been homeless talk about school. Australian Journal of Education, 55 (2), 147-160.

The National Center on Family Homelessness. (1999). Homeless children: America's new outcasts. Retrieved from http://www.colorado.edu/cye/ sites/default/files/attached-files/outcasts.pdf.

National Center for Homeless Education. (2014). Education for homeless children and youth: Consolidated state performance report data. Retrieved from http://center.serve.org/nche/downloads/data-comp1011-1213.pdf.

Obradović, J., Long, J. D., Cutuli, J. J., Chan, C., Hinz, E., Heistad, D., \& Masten, A. S. (2009). Academic achievement of homeless and highly mobile children in an urban school district: Longitudinal evidence on risk, growth, and resilience. Development and Psychopathology, 21, 493-518.

Palladino, J. M. (2009). Addressing foster care students' behavioral interventions: A national survey of teachers' opinions. Retrieved from ERIC database. (ED522808).

Popp, P. A., Grant, L. W., \& Stronge, J. H. (2008). Classrooms with revolving doors: Recommended practices for elementary teachers of at-risk and highly mobile students. Retrieved from http://center.serve.org/nche/ downloads/eff_teach_elem.pdf.

RTI Action Network. (2016). What is RtI? Retrieved from http://www.rti network.org/learn/what/whatisrti.

United States Interagency Council on Homelessness. (2015). Opening doors: Federal and strategic plan to prevent and end homelessness. Retrieved from https://www.usich.gov/resources/uploads/asset_library/ USICH_OpeningDoors_Amendment2015_FINAL.pdf.

United States Interagency Council on Homelessness. (2016). Preventing and ending youth homelessness: A coordinated community response. Retrieved from https://www.usich.gov/tools-for-action/coordinatedcommunity-response-to-youth-homelessness.

Walther-Thomas, C., Korinek, L., McLaughlin, V. L., \& Williams, B. T. (1996). Improving educational opportunities for students with disabilities who are homeless. Journal of Children and Poverty, 2(2), 57-75.

Wolfe, K., Pyle, D., Charlton, C. T., Sabey, C. V., Lund., E. M. \& Ross, S. W. (2016). A systematic review of the empirical support for Check-In Check-Out. Journal of Positive Behavior Interventions, 18 (2), 74-88.

Yell, M. L., Katsiyannis, A. \& Bradley, M. R. (2011). The evolution of special education law. In J. M. Kauffman \& D. P. Hallahan (Eds.), Handbook of special education (pp. 61-76). New York, NY: Routledge. 